\title{
Ergosterol and Patulin Contents of Conventional and Homemade Red Peppers and Hot Red Peppers Pastes
}

\author{
Nurten Yassihuyuk ${ }^{1}$, Cetin Kadakal ${ }^{\star}$ and Mustafa Otag ${ }^{2}$
}

${ }^{1}$ Food, Agriculture and Livestock Ministry, Apiculture Research Station Directorate, 52200, Ordu, Turkey

${ }^{2}$ University of Pamukkale, College of Engineering, Department of Food Engineering, 20020, Kinikli-Denizli, Turkey

\begin{abstract}
In this study; ergosterol and patulin contents of homemade and conventional pepper paste and hot paprika paste were determined and the relationships between these substances were investigated. Patulin and ergosterol were determined using high performance liquid chromatography (HPLC). A limiting value of $15 \mathrm{mg} \cdot \mathrm{kg}^{-1} \mathrm{ergosterol}$ has been proposed as an index of acceptable quality for tomato products. Ergosterol content of the 13 homemade pepper pastes were found to be lower than $15 \mathrm{mg}^{\mathrm{kg}} \mathrm{k}^{-1}$ while 8 of these over limits. In contrast, for the ergosterol content, only one of the homemade hot pepper pastes was over proposed limit while all of the conventional hot pepper pastes were lower than limits. In addition, patulin contents of all conventional and homemade pepper pastes were lower than the allowed level of $50 \mu \mathrm{g} \cdot \mathrm{kg}^{-1}$. Patulin content was significantly correlated with the ergosterol content in conventional and homemade paprika paste as 0.90 and 0.96 , respectively.
\end{abstract}

Keywords: Ergosterol; Patulin; HPLC; Pepper paste; Paprika paste

\section{Introduction}

Pepper, specifically Capsicum annuum, is a general name for plants coming from Capsicum species of Solanaceae family, whose products are used as vegetables and spices [1]. Red hot pepper is cultivated and consumed in a variety of ways in Turkey and Middle East Countries. Generally, red hot pepper is used as a spice, and in recent years it is also used in the production of hot pepper paste [2].

Pepper paste is a traditionally consumed in many countries. In its traditional use, mashed fresh fruits of Capsicum annuum are subjected to spontaneous fermentation and preserved by addition of high amounts of salt and boiling [1]. Recently, inadequate amounts of traditionally produced pepper paste and consumer demand towards more hygienic products makes the industrial production of pepper paste inevitable. Industrial production of red pepper paste is dependent on some major factors: initial micro flora, thermal processes, $\mathrm{pH}$, total soluble solids, and addition of salt and chemical preservatives [3].

Fresh hot pepper has $77-313 \mathrm{mg} .100 \mathrm{~g}^{-1}$ of ascorbic acid, 2.7-5.9 g. $100 \mathrm{~g}^{-1}$ of reducing sugars [4], and hot pepper paste contains 115-493 mg. $100 \mathrm{~g}^{-1}$ of ascorbic acid and 5.43-35.97 g.100 g $\mathrm{g}^{-1}$ of reducing sugars $[5,6]$.

Hot pepper paste is a food product known in Turkey, Spain, Mexico and Korea. Generally, hot pepper paste in Turkey is produced traditionally by sun drying. Recently, hot pepper paste has been manufactured in a plant similar to the manufacturing of tomato paste $[3,5,7,8]$. There are two main techniques applied for manufacturing of the hot pepper paste. These are concentration in an open pan and under vacuum. Production steps involve; separation of seeds and stem, washing, breaking, and concentration. In this technique hot pepper paste is manufactured without fermentation and the desired aroma does not form properly [3]. Fermentation is one of the main changes that take place during the first days of concentration of hot pepper using traditional technique. Fermentation of hot pepper paste occurs by means of natural contaminant bacteria (lactic acid bacteria) in the hot pepper [2,3].

The most important problem in dried tomatoes, dried pepper and paste industry is growth of mold. Ergosterol ( $3 \beta$-Hydroxy$5,7,22$-ergostatriene) is an important constituent of fungal cell wall and measurement of it is a useful method to detect fungal activity, which correspond to mycotoxine production. Thus ergosterol, has been recently recognized as a potential objective parameter useful for the characterization of the quality of processing tomatoes. The poor precision of the "percentage of discarded fruits" and "HMC" methods have increased the importance of ergosterol for the microbiological quality evaluation of tomato and tomato products [9].

Patulin [4-hydroxy-4 H-furo (3,2 c)-pyran-2-(6H) one], a mycotoxin which is highly toxic effect for plant and animal cells and tissues produced by several species of Aspergillus, Penicillium and Byssochlamys fungi where it is produced as a secondary metabolite, is often detected in apples. Studies with fungi or animals have demonstrated that patulin is mutagenic, carcinogenic and teratogenic. Molds contaminated from natural resources such as soil, water and air to raw materials and processed foods creating economic damage in both quality problems and led to the loss of product, as well as cause health risks. Consequently, patulin is an important quality parameter in food industry for human health [10].

The purpose of this study was to determine the contents, if any, of ergosterol and patulin in samples of pepper pastes (homemade and conventional) showing different characteristics collected from different regions of Turkey and to analyze the relationships between them.

\section{Materials and Methods}

\section{Materials}

In this research, 13 different homemade red pepper pastes and 13 different homemade hot red pepper pastes were collected from 7

*Corresonding author: Cetin Kadakal, University of Pamukkale, College of Engineering, Department of Food Engineering, 20020, Kinikli-Denizli, Turkey, Tel: 90-258 2963116; E-mail: ckadakal@pau.edu.tr

Received August 14, 2014; Accepted October 07, 2014; Published October 14 2014

Citation: Yassihuyuk N, Kadakal C, Otag M (2014) Ergosterol and Patulin Contents of Conventional and Homemade Red Peppers and Hot Red Peppers Pastes. J Food Process Technol 5: 379. doi:10.4172/2157-7110.1000379

Copyright: (c) 2014 Yassihuyuk N, et al. This is an open-access article distributed under the terms of the Creative Commons Attribution License, which permits unrestricted use, distribution, and reproduction in any medium, provided the original author and source are credited. 
different provinces (Adana, Hatay, Kahramanmaraş, Denizli, Bursa, Gaziantep and Manisa) of Turkey on September 2010 were used as material. In addition 6 different conventional and 6 different hot red pepper pastes which are produced in Turkish paste factory (Manisa, Gaziantep, Balıkesir, Manisa, Bursa and Denizli) were purchased from Turkish supermarkets on October 2010.

\section{Standard solutions}

All reagents used were analytical or HPLC grade, crystalline form of patulin (P1639, analytical reagent grade, Sigma-Aldrich Chemie GmbH Deisenhofen, Germany) and crystalline form ergosterol (E6510, analytical reagent grade, Sigma-Aldrich Chemie GmbH Deisenhofen, Germany) were used to prepare standard solutions. Also ultra pure distilled water was used for chromatographic analysis.

\section{Methods}

Determination of ergosterol: The HPLC method of Schwadorf and Müller [11] modified by Ghiretti et al. [12] was used for the determination of ergosterol in the samples. Ten grams of pepper paste samples were transferred to $500 \mathrm{ml}$ volumetric flask. $50 \mathrm{ml}$ of double distillated water was used in the transfering process. After that pepper paste was saponified with $50 \mathrm{ml}$ of methanol, $50 \mathrm{ml}$ of ethanol and $10 \mathrm{~g}$ of potassium hydroxide. The mixture was boiled for $45 \mathrm{~min}$ and the resultant reflux was filtered followed by separation in a separatory funnel with water and $n$-hexane (water/hexane; 1:2) shaking $1 \mathrm{~min}$. After that, the lower layer was collected into the erlenmeyer and the upper one was filtered over anhydrous $\mathrm{Na} 2 \mathrm{SO} 4$. The lower layer was retransferred to the separatory funnel and shaken for 2 min after adding $50 \mathrm{ml}$ of $\mathrm{n}$-hexane followed by filtration over $\mathrm{Na} 2 \mathrm{SO} 4$. The combined organic extracts were evaporated using a rotary evaporator (R-114, Buchi Rotavapor, Switzerland) to approximately $1 \mathrm{ml}$ and transferred into a $10 \mathrm{ml}$ test tube, and the content of the tubes was evaporated to dryness at $40^{\circ} \mathrm{C}$ (heating block) under a gentle stream of nitrogen. The residue was dissolved in $5 \mathrm{ml} \mathrm{n}$-hexane and $20 \mu \mathrm{l}$ portion of the solution was injected into the HPLC for the analysis.

Apparatus for HPLC: The mobile phase was n-hexane and isoamyl alcohol $(95 / 5 ; \mathrm{v} / \mathrm{v})$ with a flow rate of $2 \mathrm{ml} \mathrm{min}^{-1}$. For the analysis, a Nucleosil 100-7 C18 (250X4.6 ID mm) column, a photodiode array detector (Shimadzu, model SPD-M20 A) set at $282 \mathrm{~nm}$, a LC-20AD Shimadzu HPLC pump, a column oven (Shimadzu, CTO-20A) set at $25^{\circ} \mathrm{C}$ and a Software program (Shimadzu) were used. The sample (20 $\mu \mathrm{L}$ ) was injected with a syringe (Hamilton Co., Reno, NV, USA) into the HPLC. Coefficient of determination $\left(\mathrm{r}^{2}\right)$ was found to be $99.98 \%$ for ergosterol. The detection limits $(\mathrm{S} / \mathrm{N}=3)$ [13] ranged from $0.1 \mathrm{mg} \cdot \mathrm{L}^{-1}$ to $0.5 \mathrm{mg} . \mathrm{L}^{-1}$.

Recovery of ergosterol: In the recovery experiment, samples, for which ergosterol concentrations were predetermined, were spiked with the different concentrations of ergosterol, using aliquots at 1,2, 4, 8 and $20 \mathrm{mg} . \mathrm{L}^{-1}$, to determine the recovery of the extraction procedure in the initial step. Three determinations were carried out for each addition level. The recovery rates of ergosterol in the three different pepper pastes for 5 different concentration added to samples ranged from $98.87 \%, 98.90 \%, 99.01 \%$ within average percent recovery of $98.93 \%$.

Determination of patulin: The determination of patulin in the samples was carried out by using a Shimadzu Class-VP V5.01 high pressure liquid chromatography apparatus (Shimadzu Corp., Kyoto, Japan), as suggested by ISO (1993) for apple juice with a slight modification in extraction step. Subsample $(25 \mathrm{~g})$ was weighed into a stomacher bag added with $25 \mathrm{ml}$ of ethyl acetate and homogenized in a lab blender for $3 \mathrm{~min}$. Then the contents of the bag were filtered through a filter paper into a separating funnel. Paste pieces on the filter paper were put into the same stomacher bag and re-extracted with a second portion of ethyl acetate. The contents of the bag were filtered through the same filter paper into the same separating funnel. This process was repeated one more time (a total of three extractions per sample). Ten $\mathrm{ml}$ of $3 \%$ sodium carbonate solution was added to the separating funnel and shaken for $1 \mathrm{~min}$. Then, the phases were allowed to separate and to drained the lower aqueous layer into another separating funnel and immediately extracted with $25 \mathrm{ml}$ of ethyl acetate by shaking for $1 \mathrm{~min}$. Top layers (organic phases) were combined, transferred into a roundbottomed flask and acidified with glacial acetic acid. This extract was evaporated to dryness in a rotary evaporator. The residue in the flask was transferred into a $5 \mathrm{ml}$ volume tube by portions of $1 \mathrm{ml}$ of ethyl acetate. Then the extract was evaporated just to dryness in a water bath at $40^{\circ} \mathrm{C}$ under a gentle stream of nitrogen. The residue was dissolved in $0.5 \mathrm{ml}$ mobile phase. This final solution was kept at $-18^{\circ} \mathrm{C}$ in deep freezer until the chromatographic measurements were made.

Apparatus for HPLC: The mobile phase employed was a $10 \%$ aqueous acetonitrile solution with a flow rate of $0.5 \mathrm{ml} \mathrm{min}{ }^{-1}$. For the analysis, a Nucleosil 100-7 C18 $(250 \times 4.6$ ID mm) column, a photodiode array detector (Shimadzu, model SPD-M20 A) set at 272 nm, a LC-20AD Shimadzu HPLC pump, a column oven (Shimadzu, CTO-20A) set at $25^{\circ} \mathrm{C}$ and a Software program (Shimadzu) were used. The sample $(20 \mu \mathrm{L})$ was injected with a syringe (Hamilton Co., Reno, $\mathrm{NV}$, USA) into the HPLC. Coefficient of determination $\left(\mathrm{r}^{2}\right)$ was found to be $99.98 \%$ for patulin. The detection limits $(\mathrm{S} / \mathrm{N}=3)$ [13] ranged from $0.1 \mu \mathrm{g} . \mathrm{L}^{-1}$ to $0.5 \mu \mathrm{g} . \mathrm{L}^{-1}$.

Recovery of patulin: In the recovery experiment, samples, for which patulin concentrations were predetermined, were spiked with the different concentrations of patulin, using aliquots at $10,25,50$, $100,200,400,800 \mu \mathrm{g} . \mathrm{L}^{-1}$, to determine the recovery of the extraction procedure in the initial step. Three determinations were carried out for each addition level. The recovery rates of patulin in the three different pepper pastes for 7 different concentration added to samples ranged from $97.7 \%, 98.6 \%$, 98.9\% within average percent recovery of $98.4 \%$.

Further determinations: The $\mathrm{pH}$ of the samples was measured using a $\mathrm{pH}$ meter (PL-700PV Gondo-Taiwan) equipped with an electrode [14]. The $\mathrm{pH}$ meter was standardized by a two point method against buffer standards of $\mathrm{pH} 7.0$ and $\mathrm{pH}$ 4.0. Paste samples from each treatment were ground in a blender (Waring, USA) and juice was used to determine the soluble solids (brix) using a digital refractometer (RFM340 Bellingham Stanley, UK). The machine was standardized using purified water before readings were taken. Titratable acidity (TA) was determined as g citric acid/100 $\mathrm{ml}$ using the method of AOAC [15]. Ash amount was performed according to AOAC [16] method using burning in a furnace (Nuve MF 110, Turkey) at $650 \pm 25^{\circ} \mathrm{C}$.

Statistical analysis: Measurements were carried out in dublicates, and data were expressed as means \pm standard deviation (SD). Data were evaluated using analysis of variance (ANOVA) described by Snedecor and Cochran [17]. Comparisons of means for treatments were also done by using Duncan's multiple range tests. Significance was defined at $\mathrm{P} \leq 0.05$. Statistical analyses were performed using the SPSS statistics software package (version 16.0; IBM Corporation, Armonk, NY, USA).

\section{Results and Discussion}

Some physical and chemical properties of homemade and conventional red pepper and hot red pepper pastes obtained from different proviences of Turkey are presented in Table 1. Ash content of 


\begin{tabular}{|c|c|c|c|c|c|c|c|c|c|c|c|c|c|c|c|c|c|c|c|c|c|}
\hline \multirow[t]{2}{*}{ Sample } & \multirow[t]{2}{*}{$\begin{array}{l}\text { Number } \\
\text { of } \\
\text { Samples }\end{array}$} & \multicolumn{4}{|l|}{$\begin{array}{l}\text { Brix } \\
(\%)\end{array}$} & \multicolumn{4}{|l|}{$\mathrm{pH}$} & \multicolumn{4}{|c|}{$\begin{array}{l}\text { Acidity* } \\
\text { (\%) }\end{array}$} & \multicolumn{4}{|l|}{$\begin{array}{l}\text { Salt } \\
(\%)\end{array}$} & \multicolumn{4}{|l|}{$\begin{array}{l}\text { Ash } \\
(\%)\end{array}$} \\
\hline & & Min & Max & Mean & $S D^{* *}$ & Min & Max & Mean & $S^{* *}$ & Min & Max & Mean & $S D^{* *}$ & Min & Max & Mean & $S^{* *}$ & Min & Max & Mean & $S^{* *}$ \\
\hline HPP & 13 & 14.95 & 45.00 & 34.14 & 9.310 & 3.66 & 4.55 & 4.11 & 0.315 & 0.56 & 3.56 & 1.24 & 0.857 & 5.26 & 15.78 & 9.54 & 3.431 & 5.56 & 18.34 & 12.33 & 4.235 \\
\hline HHPP & 13 & 15.10 & 42.75 & 35.71 & 7.310 & 3.58 & 4.44 & 4.17 & 0.251 & 0.55 & 2.41 & 1.26 & 0.640 & 6.98 & 14.05 & 9.27 & 2.692 & 8.82 & 18.08 & 11.72 & 2.920 \\
\hline CPP & 6 & 21.00 & 32.00 & 25.25 & 4.875 & 4.11 & 4.58 & 4.27 & 0.198 & 0.56 & 1.26 & 0.89 & 0.248 & 1.72 & 8.50 & 4.79 & 3.287 & 2.49 & 10.10 & 6.06 & 3.409 \\
\hline CHPP & 6 & 20.00 & 36.00 & 28.33 & 7.118 & 4.09 & 4.64 & 4.40 & 0.187 & 0.52 & 0.99 & 0.74 & 0.166 & 1.79 & 7.98 & 5.68 & 2.733 & 3.61 & 10.00 & 7.99 & 2.540 \\
\hline
\end{tabular}

${ }^{*}$ Citric acid value of titration acidity

** SD : Standard Deviation

HPP : Homemade Pepper paste.

HHPP : Homemade Hot Pepper Paste.

CPP: Conventional Pepper Paste.

CHPP: Conventional Hot Pepper paste

Table 1: Brix, $\mathrm{pH}$, acidity, salt and ash content of homemade and conventional red pepper and hot red pepper pastes samples

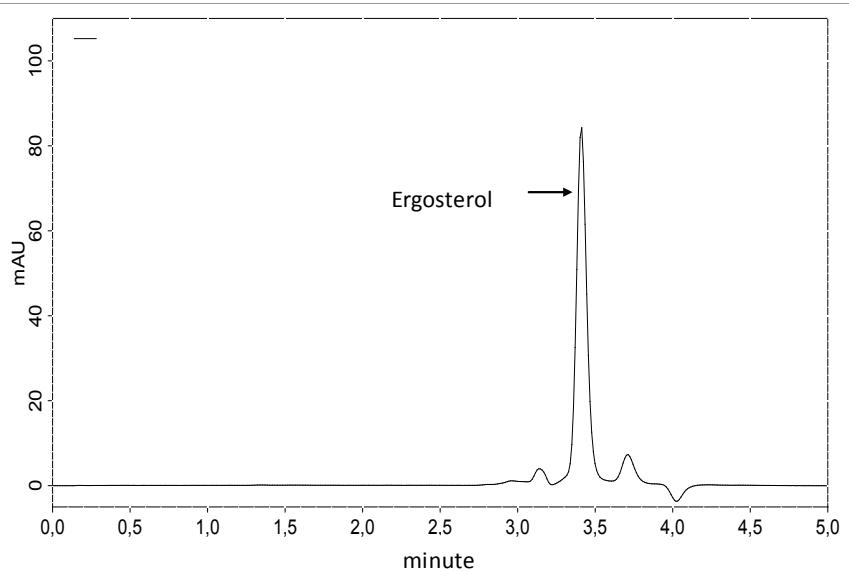

Figure 1:HPLC chromatogram of ergosterol for a sample of homemade red pepper paste

homemade red pepper was found higher compared with conventional red pepper paste. High ash contents in the homemade red pepper paste samples were thought to arise from high salt addition to homemade red pepper paste. Remaining parameters were significantly lower than the Turkish Food Codex limits. Ash content of some conventional red pepper paste was detected to be at higher levels. High ash contents in the conventional red pepper paste samples were thought to arise from high salt addition to conventional red pepper paste. The standard deviation for the homemade red pepper paste has been determined higher than that for other types of pepper pastes. Moreover, the least standard deviation value has been obtained from the conventional red pepper paste averagely.

The separation of ergosterol and patulin of homemade red pepper paste samples by HPLC were illustrated in Figures 1 and 2, respectively. The analytical method proved reliable, with detection limits of 0.1 mg. $\mathrm{kg}^{-1}$ and $0.1 \mu \mathrm{g} . \mathrm{kg}^{-1}$ for ergosterol and patulin, respectively. Ergosterol and patulin were baseline separated from other matrix components with good resolution. Identification of the compounds was achieved by comparing their retention times and UV spectrums with the data obtained from the pure reference substances [18].

Patulin and ergosterol contents of conventional red pepper paste samples with different characteristics collected from pepper paste processing plants is shown in Table 2. Ergosterol contents of pepper pastes have been measured as total ergosterol, which includes free and esterified ergosterol. Ergosterol contents of conventional pepper pastes ranged from 3.10 to $7.25 \mathrm{mg} \cdot \mathrm{kg}^{-1}$ and patulin contents of conventional pepper pastes ranged from 1.50 to $3.90 \mu \mathrm{g} \cdot \mathrm{kg}^{-1}$. Ergosterol, a suggested measure of fungal growth in plant materials, has a proposed limiting value of $15 \mathrm{mg} . \mathrm{kg}^{-1}$ for tomato products [12,19-21]. So, all these values were significantly lower than the limit. Also patulin level of these samples detected lower than maximum acceptable level of $50 \mu \mathrm{g} \cdot \mathrm{kg}^{-1}$ for fruit (apple) juices (Table 2).

The results obtained for patulin and ergosterol from the conventional hot red pepper paste samples with different characteristics collected from pepper paste processing plants is shown in Table 2 . Ergosterol content of hot red pepper paste samples from one out of six processing plants had been detected as a $1.2 \mathrm{mg} \cdot \mathrm{kg}^{-1}$. Rest of these samples did not detect ergosterol content. In addition, these samples did not detect patulin content.

Ergosterol values of all these conventional hot red pepper pastes were significantly lower than the limits. Also patulin level of these samples detected lower than maximum acceptable level of $50 \mu \mathrm{g} \cdot \mathrm{kg}^{-1}$ for fruit (apple) juices.

Patulin and ergosterol contents of homemade red pepper paste samples also were given in Table 2. Ergosterol contents of homemade pepper pastes ranged from non-detectable level to $27.1 \mathrm{mg} \cdot \mathrm{kg}^{-1}$ and patulin contents of homemade pepper pastes ranged from nondetectable level to $15.05 \mu \mathrm{g} . \mathrm{kg}^{-1}$.

Homemade red pepper paste samples from eight out of thirteen samples had high ergosterol levels exceeding the allowed level of 15 mg.kg ${ }^{-1}$ for tomatoes and tomato products. Homemade pepper paste is a sun dried (drying in shadow about 2 days) product. Therefore, the high ergosterol values in homemade pepper paste compared to conventional one may be attributable to the growing of mould in homemade pepper paste during the sun drying in shadow. It is well known that mould can propagate under sun drying conditions in shadow. In addition none of the homemade red pepper paste samples of patulin contents were fairly higher than maximum acceptable levels of $50 \mu \mathrm{g} . \mathrm{kg}^{-1}$ for fruit (apple) juices.

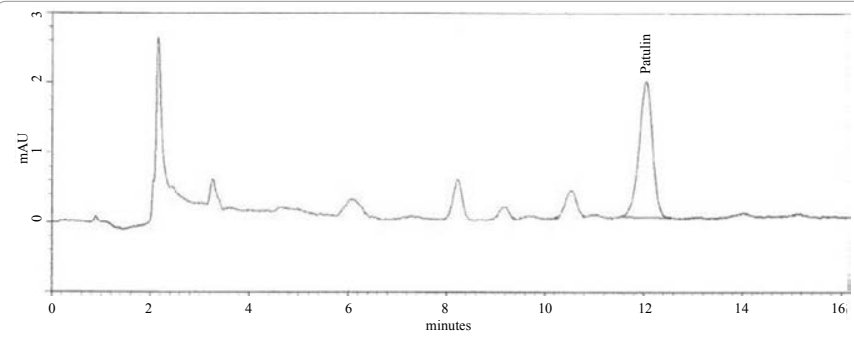

Figure 2: HPLC chromatogram of patulin for a sample of homemade red pepper paste 
Citation: Yassihuyuk N, Kadakal C, Otag M (2014) Ergosterol and Patulin Contents of Conventional and Homemade Red Peppers and Hot Red Peppers Pastes. J Food Process Technol 5: 379. doi:10.4172/2157-7110.1000379

Page 4 of 5

\begin{tabular}{|c|c|c|c|c|c|c|c|c|c|}
\hline \multirow{2}{*}{ Sample } & \multirow{2}{*}{$\begin{array}{l}\text { Number } \\
\text { of } \\
\text { Samples }\end{array}$} & \multicolumn{4}{|c|}{ Ergesterol (mg.kg-1) } & \multicolumn{4}{|c|}{ Patulin ( $\left.\mu \mathrm{g} \cdot \mathbf{k g}^{-1}\right)$} \\
\hline & & Min & Max & Mean & SD* & Min & Max & Mean & SD* \\
\hline HPP & 13 & nd & 27.10 & 16.442 & 7.645 & nd & 15.05 & 7.908 & 4.277 \\
\hline HHPP & 13 & nd & 18.35 & 6.708 & 5.096 & nd & 10.05 & 2.958 & 3.201 \\
\hline CPP & 6 & 3.10 & 7.25 & 5.083 & 1.548 & 1.50 & 3.90 & 2.725 & 0.864 \\
\hline CHPP & 6 & nd & 1.20 & 0.200 & 0.447 & nd & nd & - & - \\
\hline
\end{tabular}

nd : Non detectable Level,

* SD : Standard Deviation

HPP : Homemade Pepper paste.

HHPP : Homemade Hot Pepper Paste.

CPP: Conventional Pepper Paste.

CHPP: Conventional Hot Pepper paste

Table 2: Ergosterol and patulin contents of pepper pastes

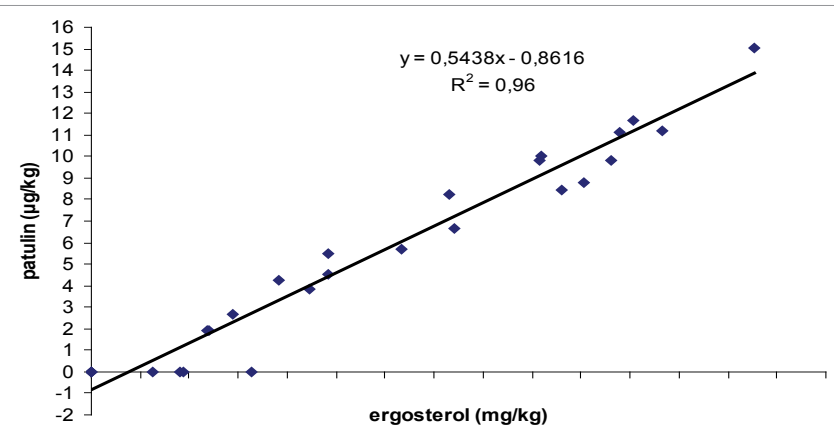

Figure 3: Regression of patulin and ergosterol concentration in homemade red pepper paste samples

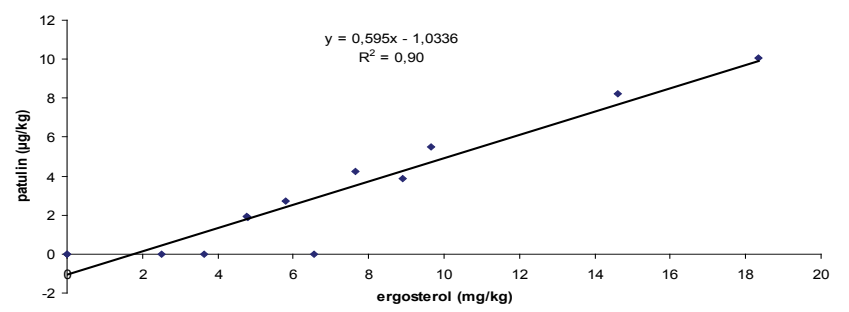

Figure 4: Regression of patulin and ergosterol concentration in homemade hot red pepper paste samples

Regressions showing ergosterol and patulin contents of homemade red pepper paste samples can be seen in Figure 3. There was significant relationship between ergosterol and patulin contents of homemade red pepper paste samples $(\mathrm{r} 2=0.96, \mathrm{p}<0.002)$.

Ergosterol contents of homemade pepper pastes ranged from nondetecTable level to $18.35 \mathrm{mg} . \mathrm{kg}-1$ and patulin contents of homemade pepper pastes ranged from non-detecTable level to $10.05 \mu \mathrm{g} . \mathrm{kg}-1$ (Table 2)

Homemade hot red pepper paste samples from one out of thirteen samples had high ergosterol levels exceeding the allowed level of 15 mg.kg-1 for tomatoes and tomato products. It was thought to arise from the substances that give hot red peppers their intensity when ingested or applied topically are capsaicin which may demonstrate inhibitory properties of mold growing. In addition none of the homemade red pepper paste samples of patulin content were fairly higher than maximum accepTable levels of $50 \mu \mathrm{g} . \mathrm{kg}-1$ for fruit (apple) juices.

Regressions showing ergosterol and patulin contents of homemade hot red pepper paste samples can be seen in Figure 4. There was significant relationship between ergosterol and patulin contents of homemade hot red pepper paste samples $(\mathrm{r} 2=0.90, \mathrm{p}<0.002)$.

\section{Conclusion}

This is the only report known to the authors concerning the presence of ergosterol in homemade and convetional pepper paste. It is also the first time that pepper products were examined in Turkey for the presence of ergosterol. In addition, there are no published data available from other countries for comparison of results of ergosterol in Turkish pepper products. Higher levels of ergosterol were found in homemade pepper paste, and much lower amounts in conventional pepper paste.

As a result of the above mentioned analyses, conventional red pepper and hot red pepper paste has been found quite safe for the human consumption. In contrast many of homemade red pepper paste samples had high ergosterol levels exceeding the allowed level of 15 mg.kg-1 for tomatoes and tomato products. It is thought there is health risks for consumers. Probably high ergosterol and patulin contents of homemade red pepper paste is result of concentrated in uncontrolled production conditions at open pan.

There was significant relationship between patulin and ergosterol contents both conventional and homemade red pepper paste samples. So the relationship between the patulin and ergosterol concentrations of pepper paste was examined to determine whether ergosterol and patulin may also be an indication of the microbiological quality of pepper pastes. Nevertheless more advanced research is needed for using ergosterol and patulin content as a quality parameter in the pepper pastes and to determine the acceptable limits in pepper paste is bring about the next stage of this study.

\section{References}

1. Luning PA, Yuksel D, Vuurst-de-Vries R, Roozen JP (1995) Aroma Changes in Fresh Bell Peppers (Capsicum annuum) after Hot-air Drying. J Food Sci 60: $1269-1276$.

2. Kuleaşan H, Okur M (2003) Industrial production of traditional red pepper paste and prevention of spoilage during storage. J Food, Agric Environ 10 241-246.

3. Bozkurt $\mathrm{H}$, Ekmen O (2003) Effects of production techniques on the quality of hot pepper paste. J Food Eng 64: 173-178.

4. Başaran MS (1979) Biber salçası yapım tekniğinin geliştirilmesi ve salçanın kalitesi üzerine araştırmalar. Çanakkale: Çanakkale Onsekiz Mart University.

5. Kızılaslan A (1993) Karaisalı tipi biber salçasının özelliklerinin iyilieştirilmesi üzerine bir araştırma. Adana: University of Çukurova.

6. Shaha RK, Rahman S, Asrul A (2013) Bioactive compounds in chill peppers(Capsicum annuum L.) at various ripening (green, yellow and red) stages. Ann Biol Res 4: 27-34.

7. Minquez-Mosquera MI, Franquelo-Camarho A, Fernandez-Diez MJ (1982) Red pepper pastes I. Colour measurement standardizasyon. Grasas-yAceites 33: 1-3

8. Byun MW, Kwon JH, Cho HO (1983) Sterilization and storage of spices by irradiation. I. Sterilization of powdered hot pepper paste. Korean J Food Sci Tech 15: 359-363.

9. Kadakal Ç, Artık N (2008) Degradation kinetics of ergosterol in tomato paste serum. Eur Food Res Tech 227: 683-688

10. Lai CL, Fuh YM , Shih DYC (2000) Detection of mycotoxin patulin in apple juice. J Food Drug Anal 8: 85-88.

11. Schwadorf K, Muller HM (1989) Determination of ergosterol in cereals, mixed feed components and mixed feed by liquid chromatography. J Assoc Offic Anal Chem 72: 457-462.

12. Ghiretti GP, Spotti E, Strina F, Sandei L, Mori G, et al. (1995) Ergosterol production by different types of moulds able to colonize tomatoes. Industry Conserve 70 : 3-12 
Citation: Yassihuyuk N, Kadakal C, Otag M (2014) Ergosterol and Patulin Contents of Conventional and Homemade Red Peppers and Hot Red Peppers Pastes. J Food Process Technol 5: 379. doi:10.4172/2157-7110.1000379

13. Li HB, Chen F (2000) Determination of silicate in water by ion exclusion chromatography with conductivity detection. J Chromatog A 874: 143-147.

14. Cemeroğlu B. (2007) Gıda Analizleri, Bizim Büro Basımevi, Kızılay,Ankara

15. AOAC (1990) Official Methods of Analysis, (15thedn), Association of Official Analytical Chemists, Arlington, VA.

16. AOAC (1997) Official Methods of Analysis, (15thedn), Association of Official Analytical Chemists, Arlington, VA.

17. Snedecor GW, Cochran WG (1987) Statistical Methods. (17thedn)., The lowa State University Press, Ames, IA, USA.
18. Kadakal C (2012) A Survey of ergosterol content of tomato products in Turkey during 2006-2010. Italian J Food Sci 24: 396-401.

19. Sio F, Laratta B, Giovane A, Quagliuolo L, Castaldo D, et al. (2000) Analysis of free and esterified ergosterol in tomato products. J Agric Food Chem 48: 780-784.

20. Bertoni P, Ghiretti GP, Sandei L, Strina F, Leoni C (1994) Ergosterol content of commercial tomato products as an index of raw material fungal contamination and proposal of a tolerance value. Industria Conserve 69: 18-25.

21. Bocchi M, Ghiretti GP, Sandei L, Spotti E, Leoni C (1995) Ergosterol production by different types of yeast able to colonize tomatoes. Industria Conserve 70: 404-409. 